\title{
Emprego da microscopia eletrônica na avaliação pós-vacinal de epitélio traqueal de patos (Anas platyrhynchos) imunizados contra a doença de Newcastle
}

[The use of scanning electron microscopy in post-vaccinal evaluation of tracheal epithelium in ducks (Anas platyrhynchos) imunized against Newcastle disease]

\author{
V.S. Franzo, A.C. Paulillo*, L.S.O. Nakaghi, L. Amoroso \\ Faculdade de Ciências Agrárias e Veterinárias - UNESP \\ Via de Acesso Prof. Paulo Donato Castellane s/n \\ 14884-900 - Jaboticabal, SP
}

\begin{abstract}
RESUMO
Avaliou-se o emprego da microscopia eletrônica de varredura no estudo da reação respiratória pós-vacinal em epitélio traqueal de patos (Anas platyrhynchos) imunizados contra a doença de Newcastle. Foram utilizadas 48 aves, distribuídas em quatro grupos: T1 - grupo de aves-controle (não vacinadas), T2 - grupo de aves vacinadas com a estirpe Ulster $2 \mathrm{C}$, T3 - grupo de aves vacinadas com a estirpe $\mathrm{B}_{1}$ e $\mathrm{T} 4$ - grupo de aves vacinadas com a estirpe LaSota. Independente do grupo experimental, as aves não apresentaram sinais clínicos detectáveis de reação respiratória pós-vacinal. Ao microscópio eletrônico de varredura, observou-se que os animais vacinados com as estirpes $\mathrm{B}_{1}$ e LaSota desenvolveram descamação epitelial da traqueia, enquanto os vacinados com a estirpe Ulster $2 \mathrm{C}$ não, mostrando um epitélio traqueal íntegro, semelhante ao do grupocontrole. Os patos vacinados com a estirpe $B_{1}$ mostraram evidências de regeneração epitelial da traqueia decorridos 21 dias pós-vacinação, o que não ocorreu com os vacinados com a amostra LaSota.
\end{abstract}

Palavras-chave: pato, microscopia eletrônica, epitélio traqueal, reação pós-vacinal respiratória, vírus da doença de Newcastle

\begin{abstract}
Scanning electron microscopy was used in the study of the post-vaccinal respiratory reaction of the tracheal epithelium of ducks (Anas platyrhynchos) immunized against Newcastle disease. Forty-eight ducks were distributed into four groups: T1 - control birds (non-vaccinated); $T 2$ - birds vaccinated with Ulster 2C strain; T3 - birds vaccinated with $B_{1}$ strain; and T4 - birds vaccinated with LaSota strain. Regardless the experimental group, birds did not show detectable clinical signs of post-vaccinal respiratory reaction. Scanning electron microscopy showed that birds vaccinated with $B_{1}$ and LaSota strains developed epithelial sloughing of the trachea, whereas those vaccinated with Ulster $2 C$ strain did not develop this change, showing intact tracheal epithelium, similar to the control group. However, the birds vaccinated with $B_{1}$ strain showed evidences of regeneration of tracheal epithelium 21 days post-vaccination, which did not happen with the ducks vaccinated with LaSota strain.
\end{abstract}

Keywords: duck, scanning electron microscopy, trachea epithelium, respiratory pos-vaccinal reaction, Newcastle disease virus

\section{INTRODUÇÃOO}

Patos são aves aquáticas de acelerado crescimento corporal, podendo ser criados em cativeiro e estão em crescente demanda no mercado de carnes exóticas de espécies silvestres e na produção de ovos. São aves muito resistentes às doenças aviárias mais comuns, que acometem galinhas (Fabichack, 2000).

A doença de Newcastle é considerada um dos problemas sanitários mais graves do plantel

Recebido em 4 de agosto de 2008

Aceito em 13 de fevereiro de 2009

Autor para correspondência (corresponding author)

E-mail: vsfranzo@hotmail.com 
avícola brasileiro, em virtude dos elevados prejuízos que ocasiona (Paulillo, 1984). Faz parte da lista A das enfermidades infecciosas do Office International des Epizzoties (International..., 1992), que reúne as moléstias cujas consequências socioeconômicas podem ser graves e de grande importância no comércio internacional de aves e seus produtos, sendo seus focos de notificação compulsória.

De acordo com Kaleta e Baldauf (1988), a doença de Newcastle tem distribuição mundial, com ampla variação de hospedeiros, inclusive aves silvestres e semissilvestres criadas em cativeiro. Tem sido relatada natural ou experimentalmente, como infectadas por seu agente etiológico, entre elas o pato da espécie Anas platyrhynchos.

$\mathrm{O}$ vírus da doença de Newcastle (VDN) replicase no trato respiratório de aves, causando destruição do epitélio traqueal (Lancaster, 1964). A ação do VDN não foi descrita no epitélio traqueal de patos, mas o foi em codornas japonesas Coturnix coturnix japonica (Santin et al., 2003) e em frangos de corte (Doreto Júnior et al., 1999).

A presente pesquisa teve o objetivo de estudar a reação respiratória pós-vacinal em epitélio traqueal de patos (Anas platyrhynchos), mediante o emprego das estirpes lentogênicas Ulster 2C, $\mathrm{B}_{1}$ e LaSota do VDN, por meio do emprego da microscopia eletrônica de varredura (MEV).

\section{MATERIAL E MÉTODOS}

Foram utilizados 48 patos machos e fêmeas, com 10 dias de vida, alojados em piso forrado com maravalha. Até o oitavo dia de vida, as aves foram mantidas aquecidas por meio de campânulas, alimentadas em comedouro tipo copo de pressão e dessedentadas em bebedouro infantil. Após esse período, a água e o alimento eram fornecidos em bebedouro e comedouro tipo copo de pressão. A dieta, à base de milho e farelo de soja, seguiu as recomendações de exigências nutricionais do NRC (Nutrient ..., 1994) e de Rostagno et al. (1983). Os patos foram submetidos às condições similares de uma criação de palmípedes.

As 48 aves foram distribuídas aleatoriamente em quatro grupos, com 12 aves cada, sendo: T1 - grupo de aves-controle (não vacinado), T2 grupo de aves vacinadas com a estirpe Ulster $2 \mathrm{C}$, T3 - grupo de aves vacinadas com a estirpe $B_{1}$ e T4 - grupo de aves vacinadas com a estirpe LaSota. Os grupos experimentais foram mantidos o mais distante possível para evitar a influência de um tratamento sobre o outro.

Foram utilizadas vacinas vivas (liofilizadas) preparadas, respectivamente, com as estirpes lentogênicas Ulster $2 \mathrm{C}, \mathrm{B}_{1}$ e LaSota, do VDN. A determinação da dose infectante $50 \%\left(\mathrm{EID}_{50}\right)$ das estirpes vacinais em estudo foram: EID $_{50}$ (Ulster $2 \mathrm{C})=10^{7,15} / 0,1 \mathrm{~mL}, \mathrm{EID}_{50}\left(\mathrm{~B}_{1}\right)=10^{7,35} / 0,1 \mathrm{~mL} \mathrm{e}$ $\operatorname{EID}_{50}($ LaSota $)=10^{7,20} / 0,1 \mathrm{~mL}$. A vacinação, via intraconjuntival, foi realizada a partir da diluição das vacinas liofilizadas, utilizando-se água destilada como diluente, na proporção de $30 \mathrm{~mL} / 1000$ doses vacinais/1000 aves, correspondente a $0,03 \mathrm{~mL}$ de dose vacinal intraconjuntival, conforme metodologia utilizada por Paulillo (1980, 1984, 1989). Todos os grupos foram observados duas vezes ao dia e qualquer manifestação clínica foi devidamente anotada.

Decorridos sete, 14 e 21 dias do período pósvacinal, quatro aves de cada grupo foram necropsiadas para colheitas de fragmentos da porção média da traqueia para avaliação dos níveis de destruição das células epiteliais, consequente à replicação do vírus vacinal.

Os fragmentos de traqueia, medindo $5 \times 8 \mathrm{~mm}$, foram fixados em solução de glutaraldeído a $3 \%$ em tampão fosfato $0,1 \mathrm{M}, \mathrm{pH} 7,6$ durante duas horas, à temperatura de $4^{\circ} \mathrm{C}$. A seguir, o material foi lavado por seis vezes consecutivas no tampão fosfato $0,1 \mathrm{M}, \mathrm{pH} 7,6$ e, então, pós-fixado em solução de tetróxido de ósmio a $1 \%$ durante 30 minutos, à temperatura de $4^{\circ} \mathrm{C}$. Decorrido esse tempo, com o mesmo tampão, o material foi novamente lavado por seis vezes consecutivas, desidratado por imersão em concentrações crescentes de álcool etílico e passado pela câmara de secagem do secador de ponto crítico, mediante a utilização de dióxido de carbono. $\mathrm{O}$ material foi então montado em um porta-objeto apropriado, recoberto com uma camada de $30 \mathrm{~nm}$ de ouro e micrografado em microscópio eletrônico de varredura ${ }^{1}$, operando em $15 \mathrm{KV}$.

\footnotetext{
${ }^{1}$ Jeol JSM 5010 - Tóquio, Japão.
} 


\section{RESULTADOS E DISCUSSÃO}

Lotes de patos vacinados, via intraconjuntival, com as estirpes $B_{1}$ (T3) ou LaSota (T4) não mostraram sinais clínicos de reação vacinal, diferente de relatos em frangos de corte, em que este tipo de vacina apresenta a desvantagem de induzir reações respiratórias indesejáveis (Allan, 1971; Doretto Júnior, 1999). No caso de frangos, a gravidade e a extensão desses sinais clínicos de reações dependem de vários fatores, entre os quais, a amostra de vírus vacinal, a presença de Mycoplasma gallisepticum e a via de administração de vacina (Beard et al., 1993).

Apesar da ausência de sinais clínicos de reação respiratória, na análise de fragmentos traqueais de aves vacinadas com as amostras $B_{1}$ (Fig. 1) ou LaSota (Fig. 2), observou-se descamação epitelial da traqueia, decorridos sete dias pósvacinal para o T4 e de 14 dias pós-vacinal, para o T3. Conforme Lancaster (1964), o VDN replicase no trato respiratório de aves, por isso, ocorreram alterações no epitélio traqueal de patos de T3 e T4. Lai e Ibrahim (1983) já haviam confirmado, por meio da análise por elétronmicrografias, que a vacinação com a cepa LaSota em pintinhos de um dia resulta em danos no epitélio traqueal das aves. Aos 21 dias pós- vacinação, as eletronmicrografias do T3 sugeriram possível regeneração epitelial, mostrando novamente a presença de cílios traqueais (Fig. 3).

É conveniente especular que, provavelmente, a ausência de sinais clínicos de reação vacinal pode ser resultante da ausência de infecções concomitantes com outros agentes, como Mycoplasma gallisepticum, capazes de exacerbar tais reações, já que as condições ambientais eram controladas. Além disso, o próprio manejo de palmípedes pode aumentar, significativamente, problemas respiratórios por ocasião do tipo de material utilizado em cama (maravalha) e, também, pela densidade de aves.

Lotes do T2 também não mostraram sinais clínicos de reação vacinal, não sendo observadas descamações epiteliais na avaliação das traqueias destas aves (Fig. 4), apesar de essa estirpe se replicar pelo trato respiratório superior. Isso é justificado, pois a amostra Ulster $2 \mathrm{C}$ é a única em que o índice de patogenicidade intracerebral (ICPI) é nulo (ICPI 0,0) e, por conseguinte, menos patogênica do que as estirpes vacinais $\mathrm{B}_{1}$ (ICPI 0,2) e LaSota (ICPI 0,4) em uso (Alexander, 1991). As eletronmicrografias do T2 foram semelhantes às do grupo $\mathrm{T} 1$.

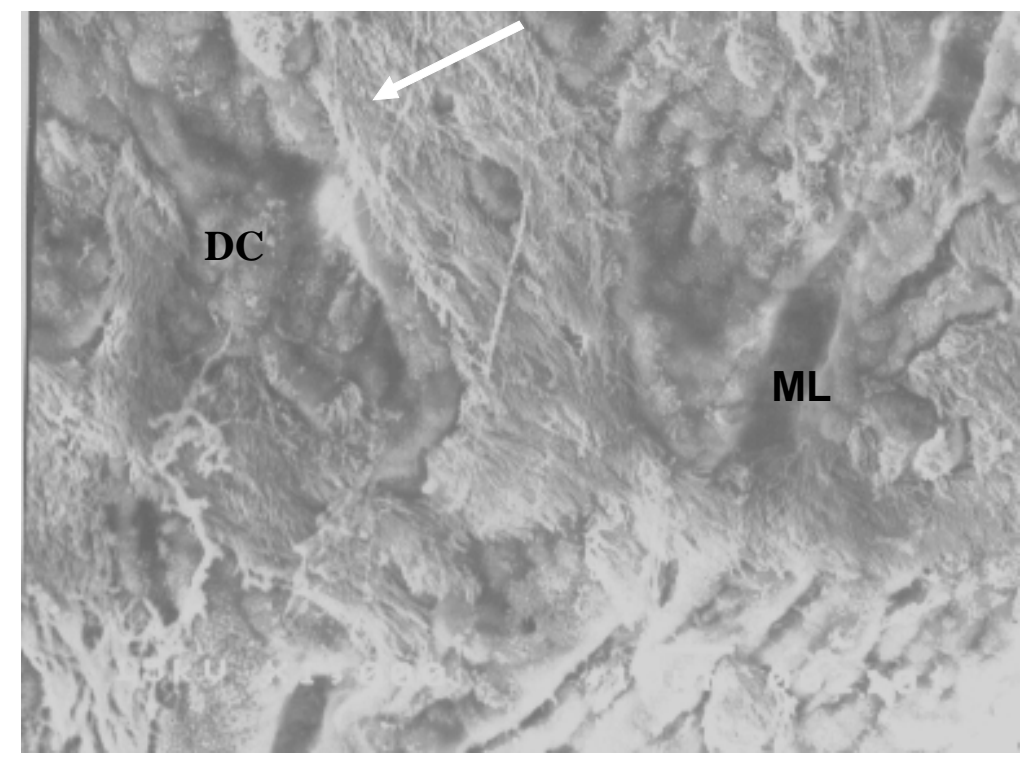

Figura 1. Eletronmicrografia de traqueia de pato (Anas platyrhynchos) colhida aos 14 dias pós-vacinação com a cepa $\mathrm{B}_{1}$. Epitélio traqueal apresentando regiões desprovidas de cílios (DC) e mucosa lesionada (ML). 


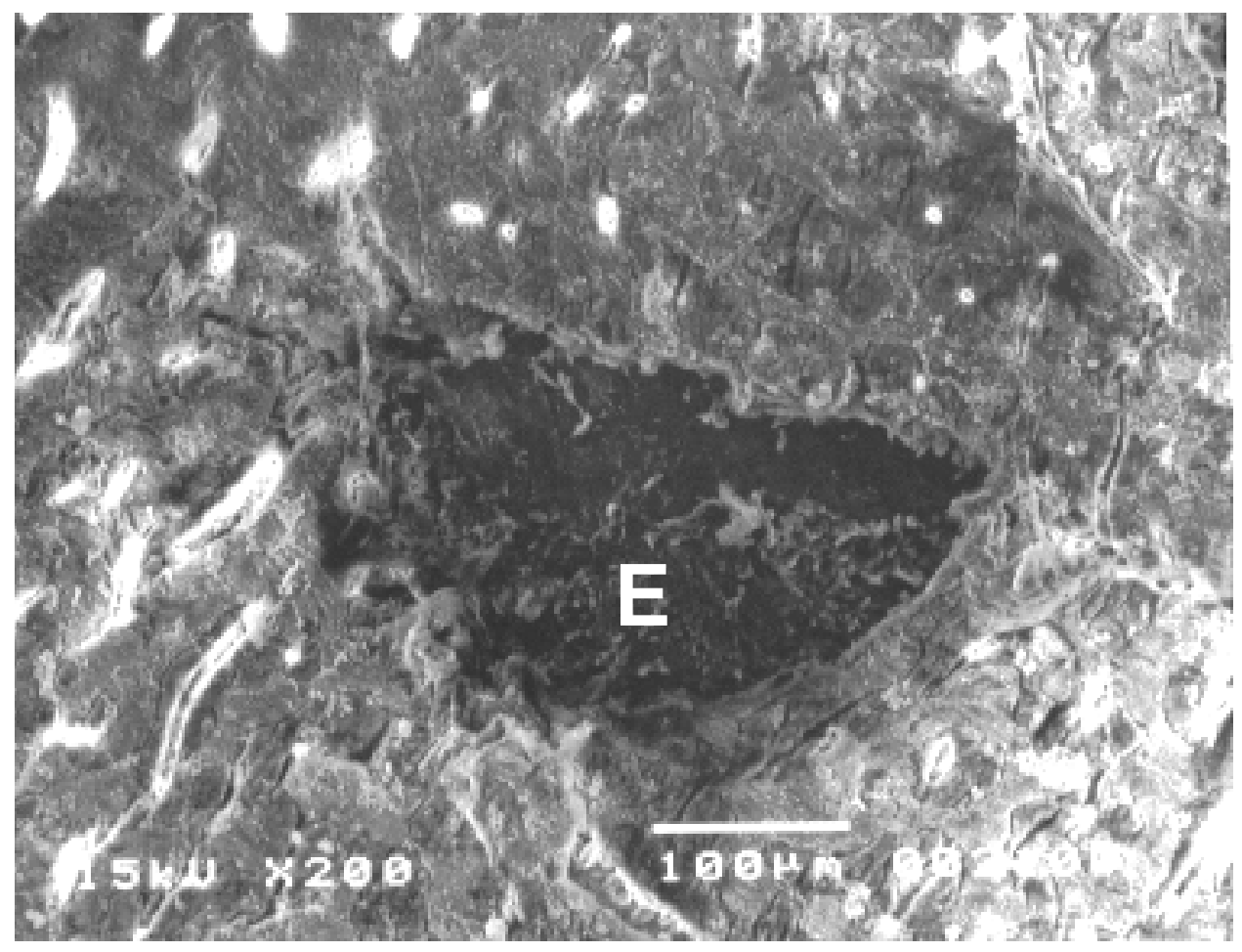

Figura 2. Eletronmicrografia de traqueia de pato (Anas platyrhynchos) colhida aos sete dias pósvacinação com a cepa LaSota, mostrando grande destruição epitelial (E).

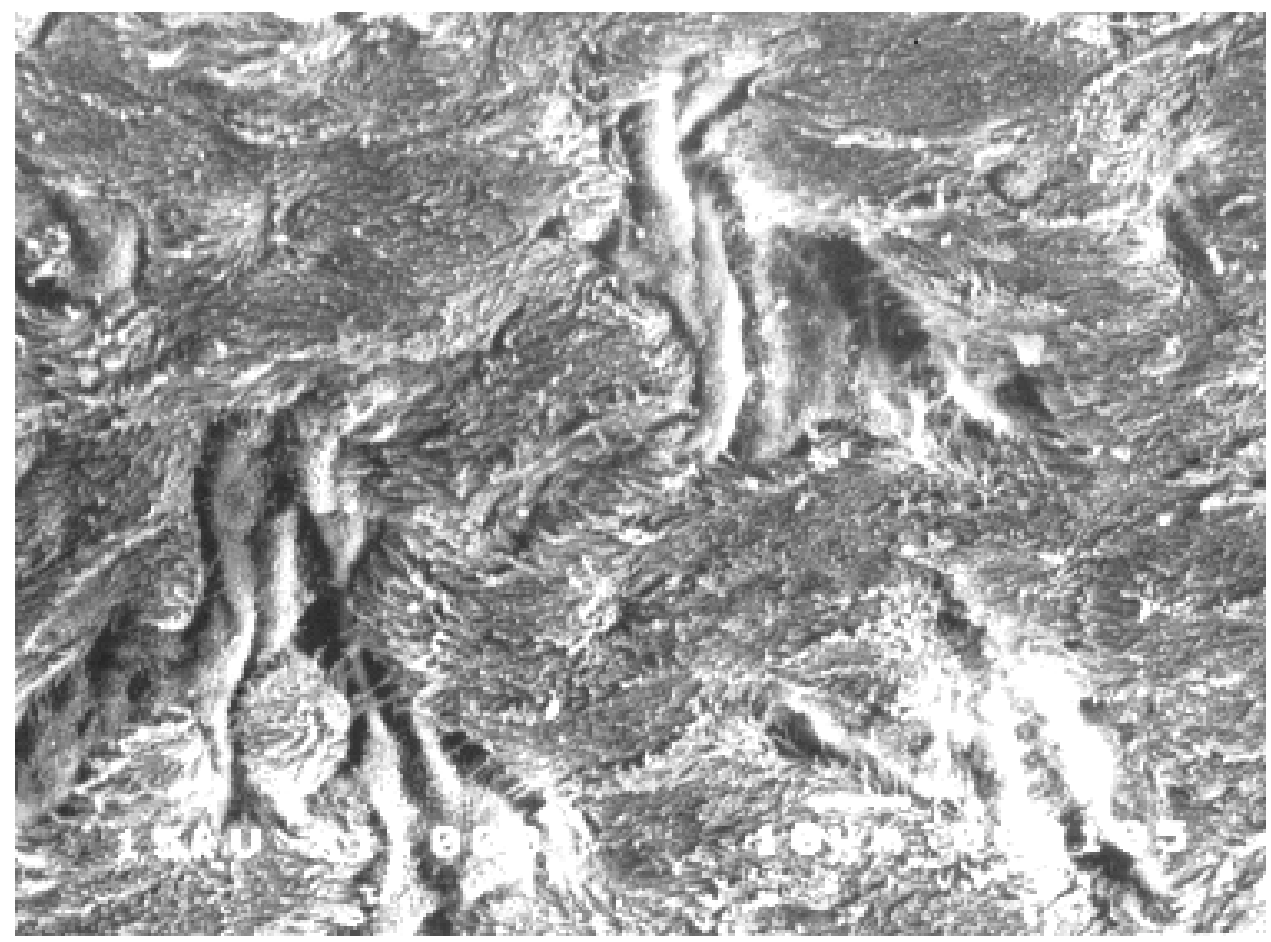

Figura 3. Eletronmicrografia de traqueia de pato (Anas platyrhynchos) colhida aos 21 dias pós-vacinação com a cepa $\mathrm{B}_{1}$, sugerindo possível regeneração epitelial, evidenciada pela presença dos cílios traqueal. 


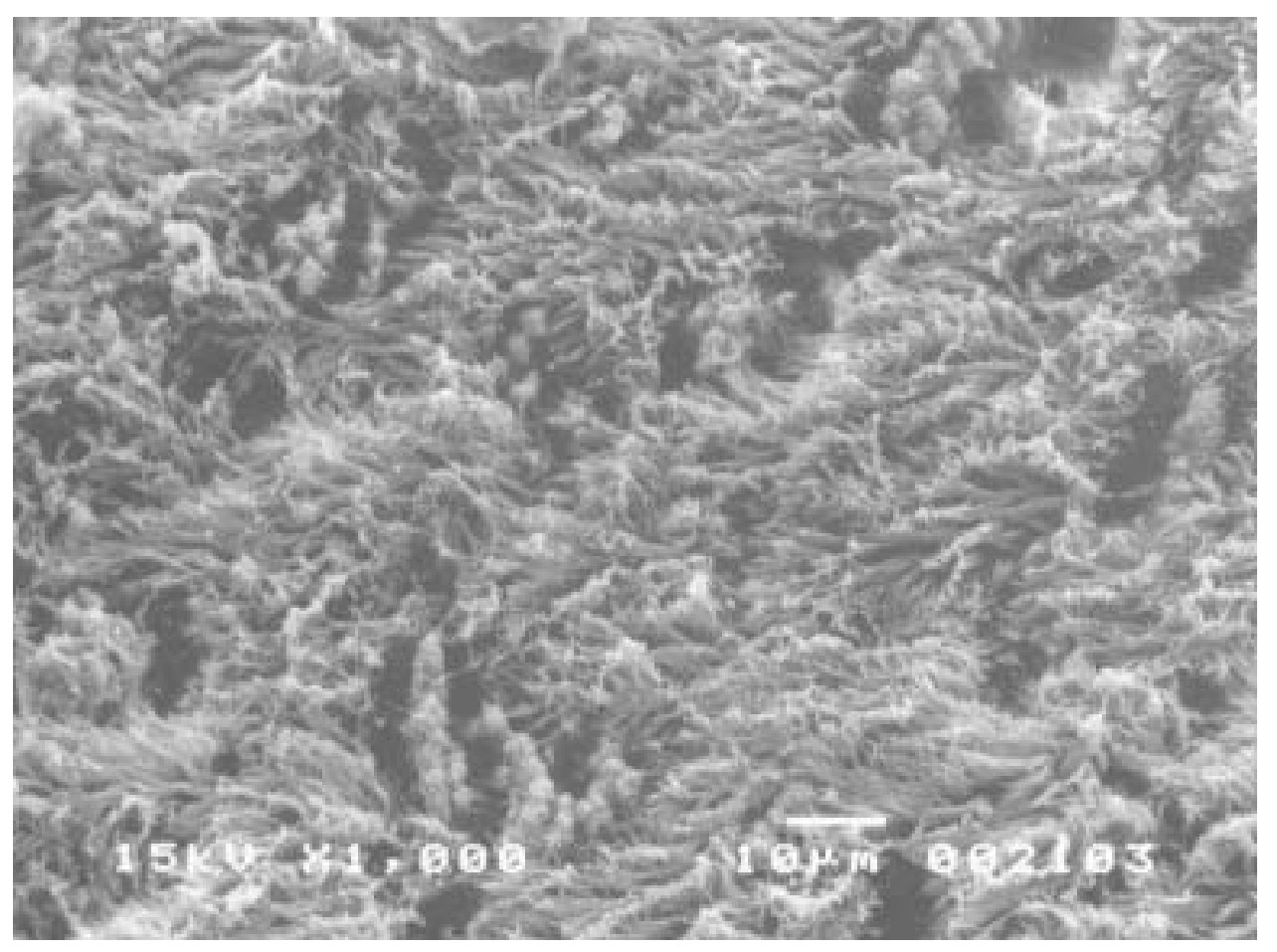

Figura 4. Eletronmicrografia de epitélio traqueal de patos (Anas platyrhynchos) do grupo Ulster 2C. Epitélio íntegro com a presença de cílios (seta).

\section{CONCLUSÕES}

Os patos da espécie Anas platyrhynchos não apresentaram sinais clínicos de reação respiratória pós-vacinal ao vírus da doença de Newcastle, independente da estirpe vacinal utilizada (Ulster 2C, LaSota, $\mathrm{B}_{1}$ ) por via intraconjuntival. Os animais vacinados via intraconjuntival com as estirpes $\mathrm{B}_{1}$ ou LaSota desenvolveram descamação epitelial da traquéia, e os vacinados com a cepa Ulster 2C apresentaram epitélio traqueal íntegro. As aves vacinadas com a cepa $B_{1}$ mostraram evidências de regeneração epitelial da traqueia decorridos 21 dias pós-vacinação, enquanto as vacinadas com a amostra LaSota não demonstraram qualquer tipo de regeneração após esse período. A microscopia eletrônica de varredura mostrouse um método alternativo, seguro e eficaz na avaliação da patogenicidade do vírus da doença de Newcastle em epitélio traqueal de patos.

\section{REFERÊNCIAS BIBLIOGRÁFICAS}

ALEXANDER, D.J. Newcastle disease and other paramyxovirus infections. In: AMES, B.W.; CALNEK, H.J.; BARNES, C.W. et al. (Eds).
Diseases of poultry. Ames: Iowa State Press, 1991. p.469-519.

ALLAN, W.H. The problem of Newcastle disease. Nature, v.34, p.124-131, 1971.

BEARD, C.W.; VILLEGAS, P.; GLISSON, J.R. Comparative efficacy of the B1 and VG-GA vaccine against velogenic viscerotropic Newcastle disease virus in chickens. Avian Dis., v.37, p.222-225, 1993.

DORETTO JÚNIOR, L.; PAULILLO, A.C.; SANTOS, J.M. et al. Utilização da microscopia eletrônica de varredura na avaliação da reação respiratória pós-vacinal em epitélio traqueal de pintos. Rev. Bras. Cienc. Avic., v.1, p.149-152, 1999.

FABICHACK, I. Criação de patos e marrecos. São Paulo: Nobel, 2000, p.01-72.

INTERNATIONAL Animal Health Code Mammals, Birds \& Bees. 6.ed. Paris: Office International des Epizooties, 1992. p.157-165.

KALETA, E.F.; BALDAUF. C. Newcastle disease in free-living and pets birds. In: ALEXANDER, D.J. (Ed). Newcastle disease. Boston: Kluwer, 1988. p.197-246. 
LAI, M.C.; IBRAHIM, A.L. Scanning electron microscopy of tracheal epithelium of chickens infected with velogenic viscerotropic Newcastle disease virus. Avian Dis., v.27, p.393-404, 1983.

LANCASTER, H.J.E. Newcastle disease control by vaccination. Vet. Bull., v.34, p.57-76, 1964.

NUTRIENT requeriments of poultry. 9.ed. Washington, DC: National Academic Press, 1994. 155p.

PAULILLO, A.C. Doença de Newcastle: estudo experimental da resposta imune às estirpes vacinais $B_{1}$ e LaSota. 1980. 84f. Dissertação (Mestrado) - Instituto de Ciências Biomédicas, Universidade de São Paulo, São Paulo.

PAULILLO, A.C. Estudo experimental da resposta imunitária às vacinas inativada (oleosa) e viva (amostra LaSota) contra a doença de Newcastle. 1984. 129f. Tese (Doutorado) - Instituto de Ciências Biomédicas, Universidade de São Paulo, São Paulo.

PAULILLO, A.C. Avaliação da resposta imune $e$ da performance zootécnica de poedeiras vacinadas experimentalmente contra a doença de Newcastle. 1989. 116f. Tese (Livre Docência) - Faculdade de Ciências Agrárias e Veterinárias, Universidade Estadual Paulista, Jaboticabal, SP.

ROSTAGNO, H.S.; SILVA, D.J.; COSTA, P.M.A. Composição de alimentos e exigências nutricionais de aves e suinos: tabelas brasileiras. Viçosa: UFV, 1983. 59p.

SANTIN, E.; LIMA, F.S.; PAULILLO, A.C. et al. The use of scaning electron microscopy in post-vaccinal evaluation of tracheal epithelium of Coturnix coturnix japonica. Cienc. Rural, v.33, p.121-124, 2003. 